\title{
INTENT TO REMEMBER AND VON RESTORFF (ISOLATION) EFFECTS REVEAL ATTENTIONAL PROCESSES
}

\author{
by \\ Krista Dawn Manley
}

A thesis submitted in partial fulfillment of the requirements for the degree

of

Master of Science

in

Psychological Science

MONTANA STATE UNIVERSITY

Bozeman, Montana

April 2012 


\section{CCOPYRIGHT}

\section{by}

Krista Dawn Manley

2012

All Rights Reserved 


\section{APPROVAL}

of a thesis submitted by

Krista Dawn Manley

This thesis has been read by each member of the thesis committee and has been found to be satisfactory regarding content, English usage, format, citations, bibliographic style, and consistency, and is ready for submission to The Graduate School.

Dr. Richard A. Block

Approved for the Department of Psychology

Dr. Colleen F. Moore

Approved for The Graduate School

Dr. Carl A. Fox 


\section{STATEMENT OF PERMISSION TO USE}

In presenting this thesis in partial fulfillment of a master's degree at Montana State University, I agree that the Library shall make it available to borrowers under the rules of the Library.

If I have indicated my intention to copyright this thesis by including a copyright notice page, copying is allowable only for scholarly purposes, consistent with "fair use" as prescribed in the U.S. Copyright Law. Requests for permission for extended quotation from or reproduction of this thesis in whole or in parts may be granted only by the copyright holder.

Krista Dawn Manley

April 2012 
TABLE OF CONTENTS

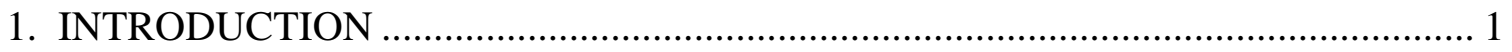

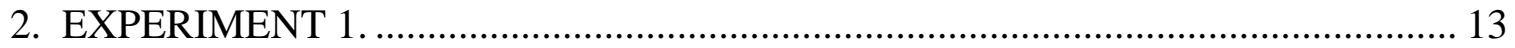

3. METHOD (1)

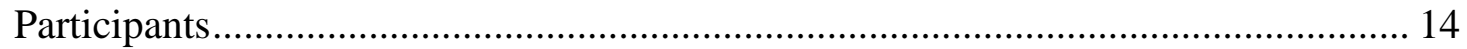

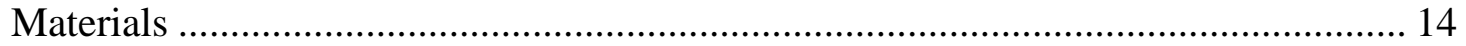

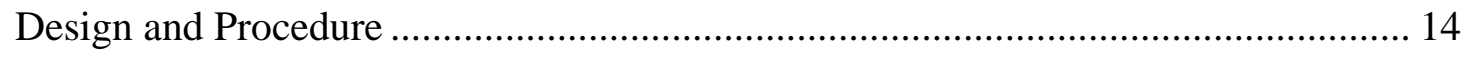

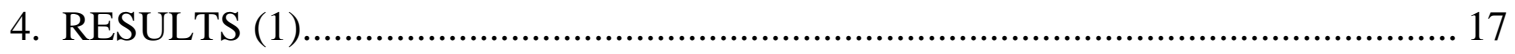

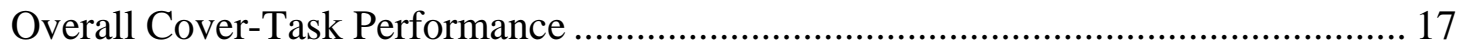

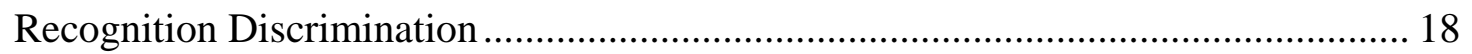

False-alarm Rate and Recognition Bias ................................................................ 20

Effects on Stimuli Preceding and Following Target Stimuli .................................... 21

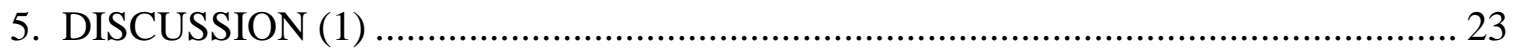

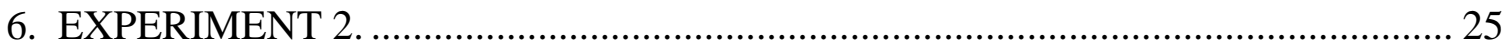

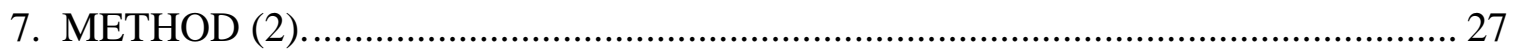

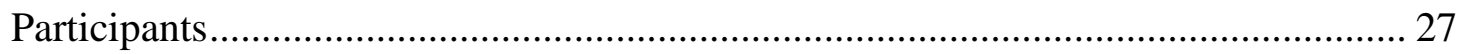

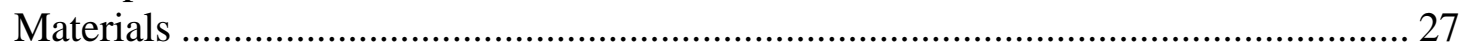

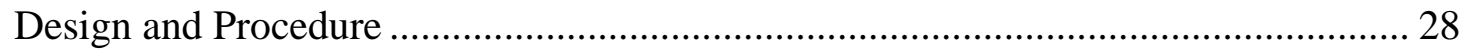

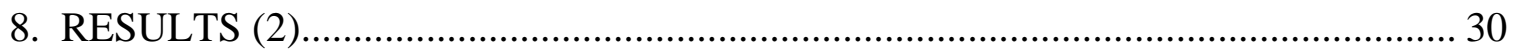

Overall Cover-Task Performance ...................................................................... 30

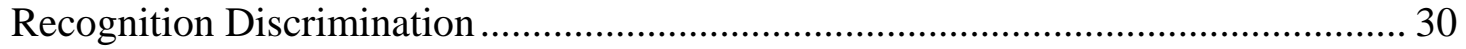

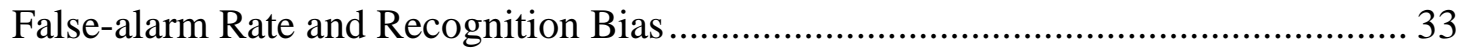

Effects on Stimuli Preceding and Following Target Stimuli ................................... 34

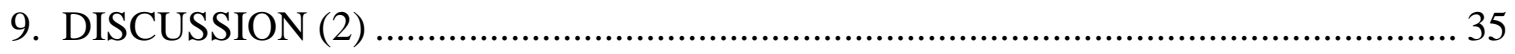

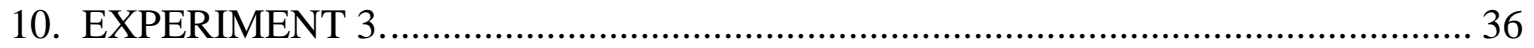

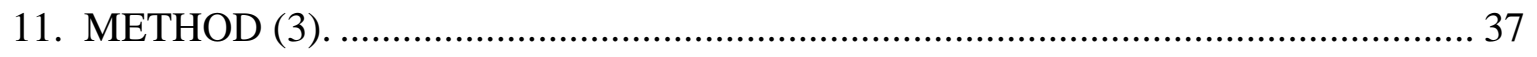

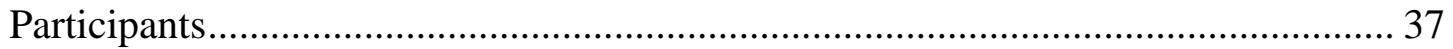

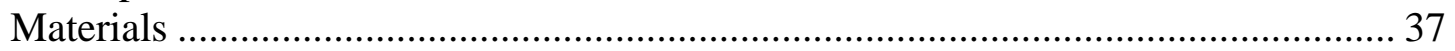




\section{TABLE OF CONTENTS CONTINUED}

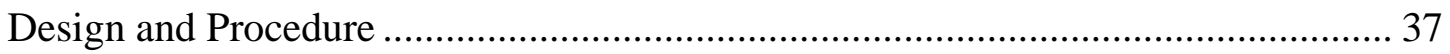

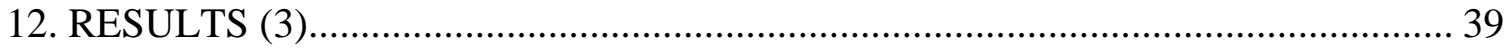

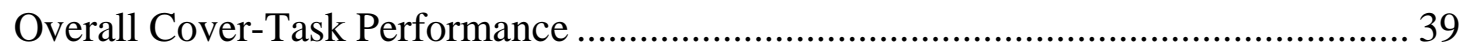

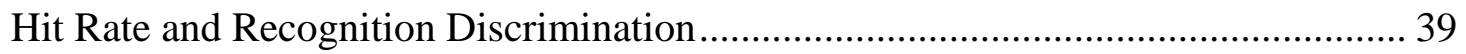

False-alarm Rate and Recognition Bias ............................................................. 42

Effects on Stimuli Preceding and Following Target Stimuli .................................... 42

Comparisons with Data from Experiment 2 ...................................................... 43

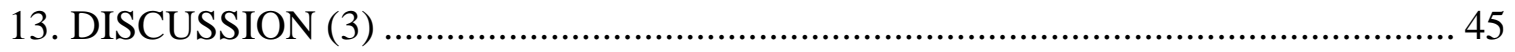

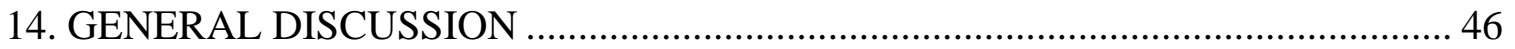

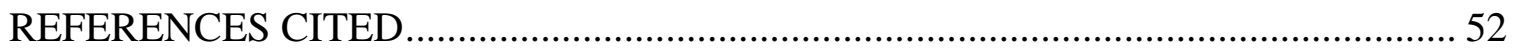




\section{LIST OF FIGURES}

Figure

1. Overall Recognition Performance of Targets (Faces)..

2. Overall recognition performance of Targets (Birds)

3. Overall recognition performance for All Conditions (Ex 2) .31

4. Overall recognition performance for All Conditions (Ex 3) .40 


\begin{abstract}
A classic finding in the memory literature is that participants remember items that are isolated, distinctive, or salient compared to items lacking in these characteristics. This finding is usually attributed to von Restorff (1933) which is when an item is isolated against a homogenous background; the learning of that isolated item is enhanced or facilitated. Block (2009) found that intent to remember a specific type of picture also enhances the subsequent recognition of it, and he suggested that increased attention to target stimuli is implicated. The three experiments reported here clarify the possible link between the attentional processes involving both of these effects. Participants saw a series of various types of pictures, with some participants being instructed to remember targets, such as human faces. The intentional memory effect was replicated. Other findings clarify the relationship between the von Restorff and intent-to-remember effects.
\end{abstract}




\section{INTRODUCTION}

Intent to remember can be simply explained as cognitively seeking to store information for future use. More specifically, intention directs attention towards a goal or purpose, so the specified information can be used in the future (Block, 2009; Neimark \& Saltzman, 1953; Postman \& Phillips, 1954; Saltzman \& Carterette, 1955). These goals of intent can take various forms of action, one of which is retention, or the goal to remember information for later retrieval. Many researchers have found that intent to remember enhances subsequent memory, such that when participants receive instruction to encode information for later use, their ensuing retrieval is enhanced (Block, 2009; Eagle \& Leiter, 1964; Fabiani \& Donchin, 1995; Hyde \& Jenkins, 1973; Neimark \& Saltzman, 1953; Postman \& Phillips, 1954; Saltzman \& Carterette, 1955; Saul \& Osgood, 1950). Divergent to this effect of intention is incidental memory, or encoding information without purpose of later retrieval, which acts as a control for intent in empirical studies (e.g., Block, 2009).

A few studies on the intent-to-remember effect have found that intent to remember information for further use does not enhance the resulting retrieval of that intentionally stored information (Bower \& Karlin, 1974; Geraci \& Rajaram, 2004, Light, Kayra-Stuart, \& Hollander, 1979). For example, Bower and Karlin (1974) found no effect of intent, but rather attributed facilitated recognition, an increased ability to identify information from a previous encounter, to rehearsal. Therefore a gap in the research remains, such that some researchers have found a positive intentionality effect on recall, but not for recognition tasks (Eagle \& Leiter, 1964; Estes \& DaPolito, 1967; 
Hyde \& Jenkins, 1973). Many of these studies contained confounds in their methodology — the stimuli they used, an orienting task that compromised the processes involved, or the diverse approaches to finding the effect (Block, 2009). For example, most used word lists which can be rehearsed, and some contained other issues, possibly washing out the effect of intent (Block, 2009; Saltzman, 1953).

Inability to find an effect of intent may have occurred because many of these studies did not have strict criteria to control for the processes that separate intentional from incidental memory. The goal of the current study is to further explore the intent-toremember effect in a paradigm that cleanly distinguishes intentional from incidental processes. Through this paradigm, the underlying mechanisms driving these distinct processes are anticipated to be exemplified, reinforcing past research that supports facilitation of memory due to intent. Additionally, while examining the positive effects of intent, the consequences of this augmented memory on background (not to be remembered) items will also be examined.

Past research supports the notion that intentional processes deviate from incidental processes in that intent is associated with controlled (automatic may be slightly involved as well) processes, whereas incidental is associated with automatic processes (Block, 2009; Hasher \& Zacks, 1979, 1984; Posner \& Snyder, 1975). Hasher and Zacks (1979) stressed that automatic processes occur without intention and therefore are associated with incidental processes, which means information is encoded without purpose of later retrieval, therefore lacking the control involved in intent (Shiffrin \& Schneider, 1977; Schneider \& Shiffrin, 1977). It is important to note that these processes 
are the main difference between intentional and incidental retention, not the quality of encoding (Hasher \& Zacks, 1984).

Extensive research has been dedicated to establishing the criteria required for a process to be considered purely automatic versus controlled. Hasher and Zacks (1979) argued that encoding operations differ mainly in regards to the effort required for humans' limited cognitive capacity or the attentional control (i.e., amount of information that can be held in an accessible state) needed. This means the operations that require negligible effort from this mechanism are considered to be automatic, and do not interfere with the continuous functioning of a limited attentional capacity (Hasher \& Zacks, 1979, 1984; Posner \& Snyder, 1975; Schneider \& Shiffrin, 1977; Shiffrin \& Schneider, 1977). In contrast, controlled processes (effortful operations) are highly demanding of attentional control, and therefore are affected by arousal and stress (Hasher \& Zacks, 1979). Controlled processes also differ from automatic processes in that they interfere with other cognitive activites that require capacity, imposing high demands on attentional control, and can show improvement from practice whereas automatic processes cannot (Hasher \& Zacks, 1979; Schneider \& Shiffrin, 1977; Shiffrin \& Schneider, 1977) . Additionally, Posner and Snyder (1975) specified that even when attention is focused elsewhere during controlled processing, a considerable amount of automatic processing is still present. In other words, conscious control cannot stop automatic processes from functioning.

Hasher and Zacks (1984) proposed that because intentional processes are associated with controlled processes, they should be manipulated via instruction prior to 
exposure to stimuli that are to be remembered. Block (2009) collected evidence supporting this conjecture by way of instruction manipulation by instructing those in the intent groups to pay close attention to stimuli they would later be tested for versus masking the task as a non-memory study (incidental groups). This manipulation was to differentiate between intentional and incidental processes from which Block concluded, supporting past research, that the processes rely on differential attentional allocation (Hasher \& Zacks, 1979, 1984; Posner \& Snyder, 1975; Schneider \& Shiffrin, 1977; Shiffrin \& Schneider, 1977). With the criteria established for automatic versus controlled processes (Hasher \& Zacks, 1979, 1984; Posner \& Snyder, 1975; Schneider \& Shiffrin, 1977; Shiffrin \& Schneider, 1977), thus establishing that intentional and incidental remembering involve different processes (Block, 2009; Hasher \& Zacks) through findings that when control is manipulated so is intent (Block, 2009), past confounds can be controlled. Subsequently, pure intentional processes versus incidental processes are exclusively tested (Block, 2009; Saltzman, 1953).

Block's (2009) extension of the intentionality research and operational definitions suggest the purpose of intentionality is to assign attentional and working memory resources to augment later retrieval (a controlled process); versus incidental memory, which is defined as encoding information without purpose of later retrieval (an automatic process). Block added that rapid encoding (under $400 \mathrm{~ms}$ ) due to directed attention (Reeves \& Sperling, 1986) is driving the intentionality effect, whereas past research attributed the effect to rehearsal or depth of processing (Bower \& Karlin, 1974). To solidify this attentional allocation hypothesis, Block (2009) sought to control for past 
confounds, by using a cover task, or cover story, instead of an orienting task, and by using pictorial stimuli (e.g., human faces) instead of word lists.

Most researchers studying intent to remember have used verbal stimuli such as words or strings of numbers (Hyde \& Jenkins, 1973; Neimark \& Saltzman, 1953; Postman \& Phillips, 1954; Saltzman \& Carterette, 1955). These types of stimuli confound the effect of intent with type of encoding, because it cannot be concluded whether or not any enhanced memory is due to rehearsal or depth of processing and do not purely test intentional versus incidental memory (Block, 2009). Therefore, in regards to the seperate processes involved, it is beneficial to use pictorial stimuli which are processed auotmatically (Palermo \& Rhodes, 2007), thereby allowing the isolation of intent on encoding processes, rather than rehearsal or depth of processing (Block, 2009; Palermo \& Rhodes, 2007). Pictorial stimulus encoding is considered special (Ellis, 1975) because unlike words, they cannot be rehearsed (Hintzman \& Rogers, 1973). This is because rehearsal does not lead to complete encoding of pictorial stimuli which are processed in the time period during which they are visible (Hintzman \& Rogers, 1973; Shaffer and Shiffrin, 1972). This is the case if the interstimulus interval (ISI) is equal to zero (Tversky \& Sherman, 1975; Watkins \& Graefe, 1981; Weaver, 1974); which means the initial picture is immediately replaced by another picture, leaving no time for rehearsal.

Evidence suggests face encoding especially relies on automatic processing, which is not to say facial encoding is completely absent of attentional control (i.e. attention is still active even when automatic processes are dominant) (Palermo \& Rhodes, 2007; Ellis, 1975). Farah, Wilson, Drain, and Tanaka (1998) found evidence that human faces 
are recognized holistically, meaning that if features are inverted or moved around, recognition drops to near chance levels (Ellis, 1975). This is important to the present research because this suggests people do not typically rely on specific facial features for recognition. Due to these strict processing criteria, Block (2009) changed the classic intent paradigm, using pictorial stimuli, and adjusted past methods to account for the specific processes involved. This allowed him to test the effects of intent to remember on recognition, without the confounds in past studies.

Using various controls in five experiments, Block (2009) tested recognition for pictorial stimuli (e.g., human faces, ape faces, or bird pictures) at various durations (0.51.0s). All participants were informed that the purpose was to assess how people process visual stimuli and were instructed to try and count the cars in all conditions as a cover task to hide the true meaning of the study. Instructions to remember were manipulated prior to presentation of stimuli in that participants were informed of a later memory test in the intent conditions, but were not in the incidental conditions. After presentation, participants reported the number of cars they had seen, then were given a recognition test where they simply circled yes or no to indicate their memory of the stimuli. The current study will use very similar methodology.

Block (2009) found that instructions to attend to and try to remember a certain type of stimulus enhanced subsequent recognition memory of that stimulus type, even if targets were presented in short time spans (0.5-1.0s). He argued that these data suggest that intent to remember leads to a rapid allocation of attentional resources, which enhances memory. This assertion is supported by the attentional gate model (Rakover, 
2002; Reeves \& Sperling, 1986). This model states controlled processes are rapid, happening in milliseconds, which Reeves and Sperling (1986) suggested to be evidence for an attentional gate that can open in under $400 \mathrm{~ms}$, allowing for effective encoding. Posner and Snyder (1975) also argued attentional processes lead to effective encoding in about 300-400 ms, supporting Reeves and Sperling’s (1986) attentional gate model. Block also argued that these data seem to reject alternative explanations; for example, increased rehearsal or more thorough processing of the target stimulus items which have been shown to enhance later memory for that stimulus (Bower \& Karlin, 1974; Craik \& Lockhart, 1972; Hyde \& Jenkins, 1973). Block specified that due to the control taken, (cover story instead of orienting task, and used pictorial stimuli rather than word lists) that past research had not, these alternatives where highly unlikely. For example, rehearsal was no longer a relevant possibility under the stringent conditions and depth of processing was not likely to be employed without instruction on this type of stimuli (Block, 2009).

The current study extends previous findings by Block (2009) to further explore the role of attentional gate mechanisms in the intent to remember effect. The major question the current study aims to answer, for which Block did not account, is what effect encoding intended targets has on background items (i.e., those items participants were not instructed to remember) versus targets items (i.e., those items participants were specifically instructed to remember). The examination of background items is important because any effect on these stimuli would resolve any alternative explanations for the mechanisms driving the intent to remember effect; either showing evidence to further 
support the attentional gate model or negating this hypothesis as the sole mechanism and create a more accurate picture of intentional encoding.

In theory, intent might work somewhat like the von Restorff effect (von Restorff, 1933; recent reviews, see Hunt, 1995; Schmidt, 1991; Wallace, 1965), also known as the isolation effect, which is the finding that if an item is isolated against a homogenous background, the learning of that isolated item is enhanced or facilitated (Wallace, 1965). This theory, like the one underlying intent-to-remember effects, relies on heightened attention towards a distinctive item (Green, 1958; 1956; Goodman, 1980; Hunt, 1995; Jenkins \& Postman 1948. Tyler, Hertel, McCallum, \& Ellis, 1979). The difference is that the isolation effect relies on the target itself being distinctive against a homogenous background (Hunt, 1995; Schmidt, 1990; Wallace, 1965), whereas the intent to remember effect does not necessarily require such isolation or distinctive targets.

Similar to the intent to remember effect, there has been some divergence on the processes driving the isolation effect (e.g. rehearsal, attention, depth of processing, etc.). Schmidt (1991) attributed the isolation effect to high priority items or stimuli participants are told to pay attention to, which have been found to be recalled and recognized better than control items. Schmidt reasoned this supported an incongruity hypothesis, which states that inconsistency leads to increased attention, thus storage of individual item information. Other researchers have concluded the isolation effect is due to rehearsal which leads to salience (Bruce \& Gaines, 1976; Geraci \& Manzano, 2010) or the effects of novelty and significance (Gati \& Ben-Shakhar, 1990). Dunlosky, Hunt, and Clark (2000) on the other hand, found that salience, exaggerated judgments of learning, and 
rehearsal are not necessary to produce an isolation effect, but that distinctiveness alone does produce it, which concurs with isolation effect reviews (see Hunt, 1995; Hunt \& Lamb, 2001; Wallace 1965 for reviews).

Hunt (1995) supported the idea that the isolation effect is caused by distinctiveness of target items or events that disrupt the dominant context. He also specified that the distinctiveness of the isolated item leads to more elaborate processing (i.e., high attention), which then produces facilitated retrieval. Therefore, heightened attention and salience lead to enhanced memory of isolated items (Hunt, 1995; Goodman, 1980; Jenkins \& Postman; 1948; Tyler et al., 1979). This is a discriminative process, which means that similarities as well as differences must be processed (Hunt, 1995; Hunt \& Lamb, 2001). This theoretical notion is what is known at the distinctiveness hypothesis as applied to the isolation effect, which states that distinctive items are remembered at a higher rate because they stimulate item-specific processing that enhances discriminability (Hunt \& Mitchell, 1978, 1982). The current study aims to provide support for Hunt’s (1995) notion that suggests the most probable mechanism underlying the isolation effect (like the intent-to-remember effect) is increased attention.

Similar to intent to remember research, the results regarding the isolation effect have been somewhat inconclusive. For example, some research has found evidence for the isolation effect only in recall, never in recognition (McDaniel \& Einstein, 1986; McLaughlin, 1968; van Dam, Peeck, Brinkerink, \& Gorter, 1974) and only within subjects, but not between subjects (McDaniel \& Einstein, 1986). In regards to the outcome the isolation effect might have on background items, again those items that 
precede or follow target or isolated items, some researchers have reported decreased memory for immediately preceding or immediately following stimuli (Ellis, Detterman, Runcie, McCarver, \& Craig, 1971; Schmidt, 1985; Schmidt, 1991; Schulz, 1971; Tulving, 1969; Waugh, 1969). Brown and Kulik (1977) alternatively found that the distinct items that led to the isolation effect increased memory for background items. Also comparable to intent studies, a considerable majority of isolation studies have used word lists to elicit an effect, which again is subject to confounds like rehearsal. In a unique study that used pictures rather than words, Ellis et al. (1971) found evidence of the isolation effect (photos of nude humans) in both the recall and recognition, but discovered significantly decreased memory for two items preceding and the six items following the nude photos. This may be evidence that pictorial stimuli is a sufficient control for confounds that have prevented an isolation effect from being exhibited in recognition in past studies.

In addition, some research has shown that intent to learn is an important variable and likely even critical to produce an isolation effect because elaborative processing may be required for effective encoding (Fabiani \& Donchin, 1995; Postman \& Phillips; Saltzman \& Carerett, 1959; Saul \& Osgood, 1950; Wallace, 1965). In contrast, Geraci and Rajaram (2004) found evidence that the isolation effect occurs without conscious recollection or controlled processes (i.e. intent). Light et al. (1979) in a study that specifically tested distinct faces versus prototype faces found an isolation effect, but memory performance was similar in intentional and incidental conditions, indicating intent might not be essential to produce an isolation effect. 
Considering the isolation effect is similar to the intent to remember effect, isolation research has likely suffered from the same confounds as intent research; thus by applying the strict controls to the isolation effect as has been done to intent research, an effect can be found, while also examining the consequences on background items of both the isolation effect and intent to remember.

The current study follows the logic that if intent-to-remember instructions operate like the isolation effect—attracting attention to distinctive (target) stimuli-there might also be effects on immediately preceding or following stimuli. According to Block (2009), intending to remember did not seem to affect other items, but these other items were not directly tested. As discussed, isolation research has been largely inconclusive in this regard which leads us to the current study.

One way to decide among the suggested explanations is to assess participants’ ability to report recognizing an item that immediately preceded or followed a distinct, or isolated, item or items. Memory performance for preceding or following items is compared to performance for other items in the series (i.e., those that were not distinct and did not immediately precede or follow target item or items) to in turn determine the underlying mechanisms driving the effects and rule out alternative theoretical possibilities. Theoretical possibilities include these three major variants: (a) presentation of a target (to-be-remembered) stimulus might disrupt consolidation of an immediately preceding stimulus preventing the item from complete encoding and reduce memory for the preceding item; (b) rehearsal of a target stimulus even after it is replaced immediately 
(at ISI $=0$ ) might impair memory for a following stimulus; or (c) arousal to a target stimulus might persist so as to enhance memory for a following stimulus.

The present experiment was designed to test alternative explanations to Block's (2009) attentional resource explanation by utilizing the isolation effect. In past research the isolation effect has been manipulated three ways: within list, such that one word of twenty may be in red ink while the others are in black; by material, such that a non-word is placed in a list of words; or by structural organization, such that one word type is embedded into another (Schmidt, 1991; Wallace, 1965). In Experiment 1, structural organization was the most equivalent, whereas Experiment 2 was an exploratory method (distinct items were framed) comparable to within list, as was Experiment 3 (distinct items tinted red). In the current study, I will continue to operationalize intentional versus incidental conditions similarly to Block (2009): Intent to remember involves allocating attentional and working memory resources to augment long term memory (a controlled process); versus incidental, which is encoding information without purpose of later retrieval (an automatic process). 


\section{EXPERIMENT 1}

The current study was based on Block’s (2009, Experiments 2 and 3) basic methodology with additional controls to test for isolation effects. Theoretically, the isolation effect could work like intent to remember if participants are instructed to attend to specific targets, such as faces in a series consisting of many types of pictorial stimuli. Participants were tested on both target and non-target stimuli in the same experiment, in contrast to Block (2009), in which participants were tested on human faces and bird pictures, respectively, in two different experiments. Based on past research, predictions are exploratory considering the inconclusive nature of former conclusions on the effects both isolation and intent to remember have on background items. Additionally, I expected to replicate Block’s (2009) finding of recognition facilitation due to intent. 


\section{METHOD}

\section{$\underline{\text { Participants }}$}

A total of 87 Montana State University undergraduate students consented to participate in a study investigating how people process visual information. They were run in sessions (groups) of about 8-10 subjects each.

\section{$\underline{\text { Materials }}$}

The same monochrome pictures were used that Block (2009) utilized from Carmel and Bentin (2002) with average distinctiveness. This is to control for a potential confound that distinctive items are easier to recognize (Going \& Read, 1974; Light, Kayra-Stuart, \& Hollander, 1979). I selected 18 pictures of automobiles (cars), 39 of human faces (19 female and 20 male faces), and 39 of birds. Although they were selected from the same set, the pictures differed from those used in previous research (e.g., Block, 2009; Carmel \& Bentin, 2002).

\section{Design and Procedure}

The basic design was a $3 \times 2 \times 2$ mixed model, with Memory Condition (faceintent vs. bird-intent vs. incidental) and Stimulus Type (target vs. nontarget) manipulated between subjects and Test Type (faces vs. birds) manipulated within subjects. In each session, about an equal number of subjects were given instructions to attend to faces, to attend to birds, or to attend to neither (no attentional instructions). Thus, in each session there were three between-subjects conditions, with an approximately equal number of 
subjects in each condition.

In order to prevent participants in the incidental condition from effortfully trying to remember the presented stimuli, at the start of the experiment all participants were given a cover task: They read written instructions saying that they would see a series of automobiles (cars), human faces, and bird pictures, and that their task was to count the total number of cars they saw. Memory condition was manipulated by written instructions informing participants in the intentional condition that they would subsequently be asked to recognize the faces (or birds) that they saw. Participants in the incidental condition did not receive this information.

Participants then viewed 76 stimuli-18 cars, 29 faces, and 29 birds. The ISI was 0 sec. Presentation stimuli were randomly assigned to the 76 serial positions. Additional within-subjects conditions involved whether targets or nontargets preceded or followed targets or nontargets. Thus, there were four conditions testing for effects on preceding items: target preceding target (TPT), target preceding nontarget (TPN), nontarget preceding target (NPT), and nontarget preceding nontarget (NPN). There were also four conditions testing for effects on following items: target following target (TFT), target following nontarget (NFT), nontarget following target (TFN), and nontarget following nontarget (NFN). A few adjustments were made to the random series in order to equate (at 10 each) the number of preceding and following stimuli in each of the conditions. A second presentation series was formed by reversing the serial positions of the stimuli in the series for approximately half of the subjects. This effectively rotated various 
conditions of interest; for example, TPN (or NFT) items became NPT (or TFN) items, and so on.

After the pictures were presented, participants were first asked to report the total number of cars that they saw. Then they were asked to make old-new recognition judgments on a total of 78 stimuli, half (39) faces and half (39) bird pictures. Of these, 29 faces and 29 birds were previously presented (old), along with 10 new faces and 10 new birds. Each was randomly assigned to the test series and was shown for 8.0 sec. Several pictures were scored twice on the subsequent recognition test, such as for both a NFT item and as a NPN item. 


\section{RESULTS}

Recognition performance was analyzed using the recommended method and correction of Snodgrass and Corwin (1988). Two alternative measures of discrimination and bias were also analyzed in all experiments: the $A^{\prime}$ (recognition discrimination) and $B^{\prime \prime}{ }_{\mathrm{D}}$ (recognition bias) measures and the logistic signal-detection measures of accuracy $\left(d^{\prime}\right)$ and response bias $(C)$ for all participants and item types (see Snodgrass \& Corwin, 1988). However, no analysis revealed any pattern of findings different from the $P_{\mathrm{r}}$ (recognition memory) and $B_{\mathrm{r}}$ (bias) measures; that is, each main effect and interaction effect was consistently either significant or nonsignificant, regardless of which model of recognition discrimination and bias was used.

Several mixed-model ANOVAs were conducted to compare performance in the various conditions. Planned comparisons ( $t$ tests) were conducted to clarify differences between theoretically important conditions involving preceding or following stimuli.

\section{Overall Cover-Task Performance}

The overall number of cars reported $(M=17.90, S E=0.14)$ did not differ significantly from the actual number of 18 cars presented $[t(86)=0.58, p=.56]$.

Participants in the two (combined) intentional conditions $(M=17.97, S E=0.20)$ and one incidental condition $(M=17.83, S E=0.15)$ showed comparable performance $[t(85)=$ $0.47, p=.64]$. 


\section{$\underline{\text { Recognition Discrimination }}$}

Preliminary evidence concerns recognition discrimination $\left(P_{\mathrm{r}}\right)$ as a function of memory condition, stimulus type, and their interaction. The results of a $3 \times 2 \times 2$ mixed model ANOVA, on recognition discrimination revealed a main effect of memory condition, such that participants in the intention conditions recognized overall more stimuli, whether it was birds or faces. To confirm this effect of intent, I collapsed the intentional memory conditions together to compare them against the incidental condition in an ANOVA. Mean $P_{\mathrm{r}}$ was greater in the two intentional conditions than in the incidental condition $[F(1,85)=11.5, p=.001, d=0.77$, a large effect $]$. This effect replicates previous research (Block, 2009). Neither the main effect of stimulus type nor the interaction between memory condition and stimulus type was significant (both Fs < 1). The pattern of significant and nonsignificant effects on the recognition hit rate (not reported herein) was the same as on recognition discrimination.

Although the nonsignificant main effect of stimulus type (target vs. nontarget) may seem surprising, this is clarified by two mixed-model $2 \times 2$ (Memory Condition: intentional vs. incidental $\times$ Stimulus Type: targets vs. non-targets) ANOVAs, which were conducted separately for each test type (faces vs. birds). Again only a main effect of memory condition was found $[F(1,85)=12.1, p=.001, d=0.78]$ and no effect of stimulus type, $p=.35$. Figure 1 shows data for participants instructed to remember faces (versus the incidental-memory control condition, in which subjects were also scored on face recognition). 


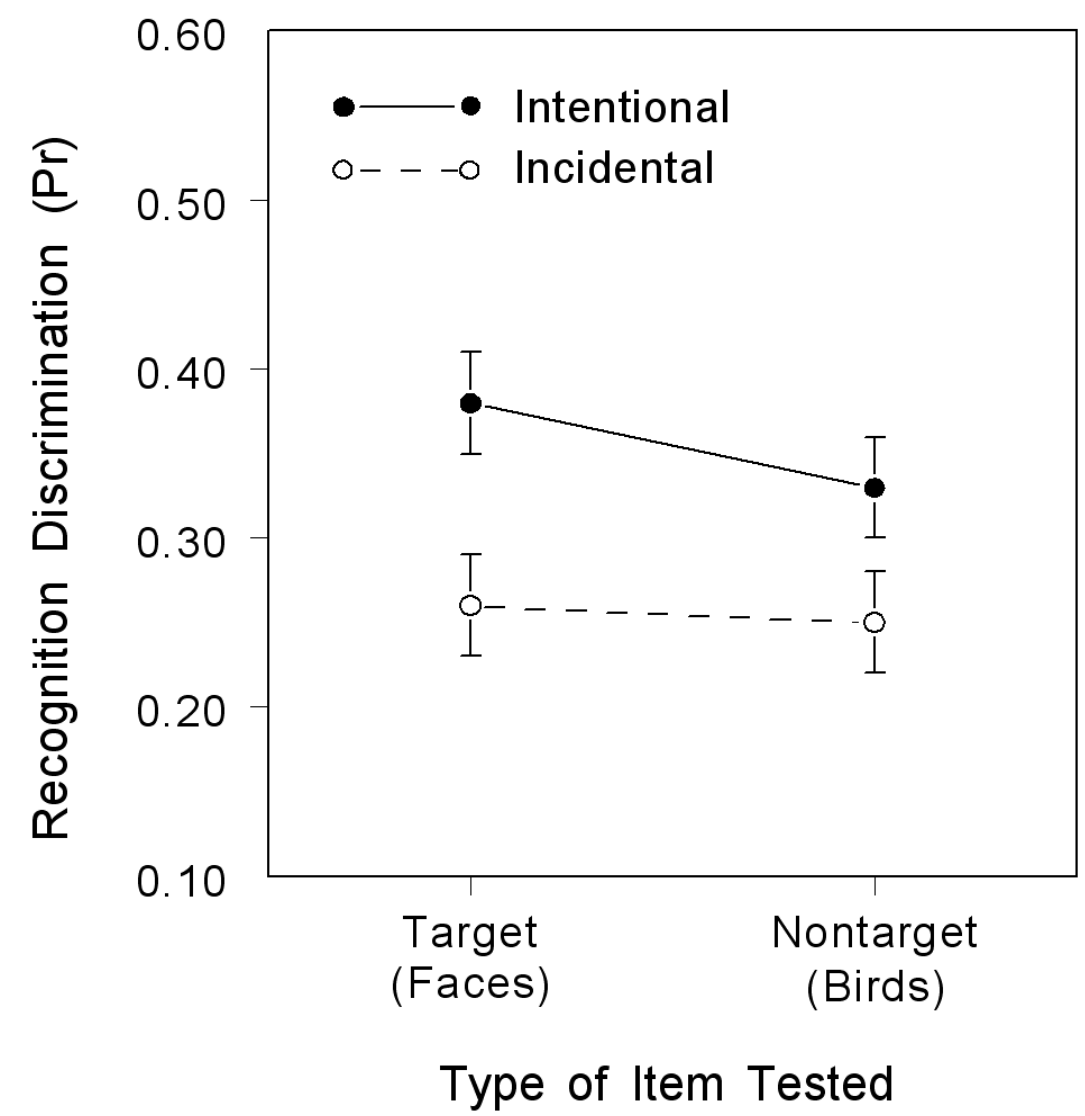

Figure 1. Overall recognition performance $\left(P_{\mathrm{r}}\right)$ in intentional (subjects told to attend to faces) and incidental conditions on faces (as targets) versus birds (as nontargets). Error bars show the SE of each mean.

Figure 2 shows data for participants instructed to remember birds (versus the incidental-memory control condition, in which subjects were now scored on bird recognition. Although recognition for faces versus birds was in the direction of significance, regardless of memory condition, it never achieved it $(p=.09)$. 


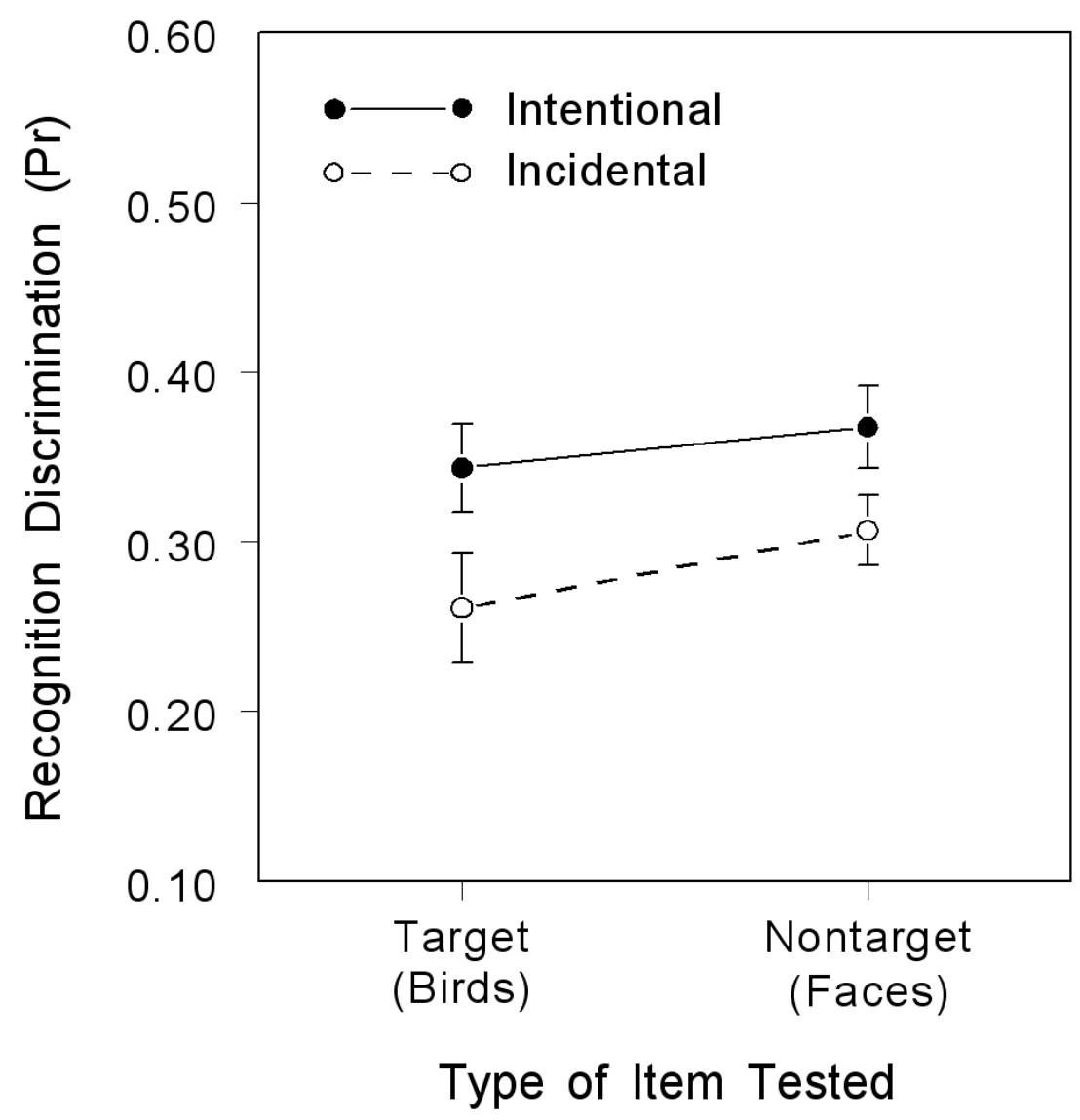

Figure 2. Overall recognition performance $\left(P_{\mathrm{r}}\right)$ in intentional (subjects told to attend to birds) and incidental conditions on birds (as targets) versus faces (as nontargets). Error bars show the SE of each mean.

\section{False-alarm Rate and Recognition Bias}

Two mixed model $2 \times 2$ (Memory Condition: intentional vs. incidental $\times$ Stimulus Type: target vs. non-target) were conducted, one on the false-alarm rates and one on recognition bias $\left(B_{\mathrm{r}}\right)$, as these two measures are correlated (Snodgrass \& Corwin, 1988). For each ANOVA, the data were collapsed over Test Type (faces vs. birds) because there was no main effect of test type, and test type did not interact with other variables, $F$ 's $<1$. 
The overall false-alarm rate was fairly low $(M=0.21, \mathrm{SE}=0.02)$ and not significantly different from zero $(p=.43)$.

The main effect of memory condition was not significant $[F(1,85)=1.47, p=$ $.23, d=0.20$ ]. The main effect of stimulus type and the Memory Condition $\times$ Stimulus Type interaction were both marginally significant $[F(1,85)=3.60$ and $3.30, p=.06$ and $.07, d=0.19$ and 0.27 , respectively]. The overall recognition bias $\left(B_{\mathrm{r}}\right)$ was conservative $(M=0.28, \mathrm{SE}=0.16)$. The main effect of memory condition on $B_{r}$ was not significant $(F$ $<1$ ). The main effect of stimulus type and the Memory Condition $\times$ Stimulus Type interaction were both significant $[F(1,85)=4.38$ and $7.11, p=.04$ and $.01, d=0.07$ and 0.24 , respectively]. These effects neither increase or decrease understanding of intent and isolation, so no further detail will be given.

\section{Effects on Stimuli Preceding and Following Target Stimuli}

Several planned comparisons (within-subjects $t$ tests) on $P_{\mathrm{r}}$ values revealed the important finding of no significant effect on pictures that preceded or followed a target stimulus. This concurs with no earlier reports about isolation effects, in that they sometimes result in either a detriment or a facilitation to background items (Brown and Kulik, 1977; Ellis et al., 1971); Schmidt, 1985; Schmidt, 1991; Schulz, 1971); Tulving, 1969; Waugh, 1969). Effects on a preceding stimulus were not significant [all ts(28) < 1.22 , $p s>.23, d s<0.23$ ], and effects on a following stimulus were also not significant [all ts(28) $<0.93, p s>.36, d s<0.15]$. 
Specifically, with intent to remember faces (as targets), there was no effect on a preceding stimulus: Recognition of a target in TPN versus TPT conditions did not differ $[t(28)=1.04, p=.31, d=0.17]$, and recognition of a non-target in NPN versus NPT did not differ $[t(28)=0.16, p=.87, d=0.03]$. There was also no effect on a following stimulus: Recognition of a non-target in NFN versus NFT did not differ $[t(28)=0.43, p=$ $.67 d=0.07]$, and recognition of a target in TFN versus TFT did not differ [t(28) $=0.11$, $p=.92, d=0.02]$.

With intent to remember birds (as targets), there was no effect on a preceding stimulus: Recognition of a target in TPN versus TPT conditions did not differ $[t(28)=$ $1.22, p=.23, d=0.23$ ], and recognition of a non-target in NPN versus NPT did not differ $[t(28)=0.38, p=.71, d=0.09]$. There was also no effect on a following stimulus: Recognition of a non-target in NFN versus NFT did not differ $[t(28)=0.93, p=.36, d=$ $0.15]$, and recognition of a target in TFN versus TFT did not differ [t(28) $=0.70, p=.49$, $d=0.13]$ 


\section{DISCUSSION}

The main finding of Experiment 1 was the replication of Block (2009) in that there was a significant benefit of intent to remember on recognition. Additionally, background items were not significantly influenced by memory for the target items as determined by the isolation and intent to remember effects. Therefore because there was no effect on recognition of items that preceded or followed targets versus nontargets, several hypotheses about intent to remember are weakened, if not completely rejected. First, the presentation of a target (to-be-remembered) stimulus did not seem to disrupt consolidation of a preceding stimulus. Recognition of target stimuli was not detrimental to preceding stimuli. Thus, these data reject the consolidation interruption hypothesis. Second, the rehearsal of a target stimulus even after it was replaced immediately (at ISI =

0) did not impair memory for a following stimulus, and recognition for following stimuli was not significantly lower than for target stimuli; this rejects a rehearsal hypothesis. The arousal hypothesis, which holds that arousal to a target stimulus might persist and enhance encoding of a following stimulus, is also rejected. This was not the case as recognition of following stimuli was neither better nor worse than of target stimuli. Consequently, Experiment 1 seems to support the attentional-gate model that Block (2009) proposed was the instigator, thus concluding that the enhancement of recognition memory in the intentional condition is attributable to the rapid allocation of attentional resources.

Again, Block (2009) found that intent did not seem to disrupt recognition for background items, but did not specifically test them as in the current study. The addition 
of the isolation effect may have influenced a change, therefore needs to be re-examined by separating the two effects. Past research regarding the isolation effect generally used one or two target or isolated items; in Experiment 1 there were 29, which may have been too many to make the targets distinct. On that note, any isolation effect may not have been strong enough, or the stimuli targets distinct enough, disabling the isolation effect. To explore these possible issues, I conducted a second experiment addressing a reexamination of target proportions, as well as the isolation effect itself. 


\section{EXPERIMENT 2}

The purpose of Experiment 2 was to explore the possibility that the isolation effect may or may not be accountable for heightened memory of target items. From Block (2009) and Experiment 1, these effects are likely due to increased attention, but is the resulting increased recognition due to the isolation effect or intent to remember? To answer this question, I sought to re-examine the manipulations three ways: (a) by changing the number of target stimuli from 29 to 7 more distinct targets, (b) by creating a more distinct isolation by putting white frames around target stimuli in the isolation conditions, and (c) by testing isolation directly by including a condition where the effect is tested without intent.

In Experiment 2, background items were tested (preceding faces and following faces), as well as target items (framed faces), and items that classify as neither targets nor background items (other faces). Predictions for Experiment 2 are again exploratory due to the mixed and inconclusive research of the past, especially because it explores a new isolation manipulation (frames). Past research suggests that the isolation effect is due to increased attention (Hunt, 1995; Goodman, 1980; Jenkins \& Postman; 1948; Tyler et al., 1979); intent to remember is also due to increased attention (Block, 2009). Increased attention has been shown to increase memory (Posner \& Snyder, 1975); however, it is unclear exactly what processes produce this effect. One way to determine this again is to assess remembering for an item that immediately preceded or followed a distinct, or isolated, item or items. Theoretical alternatives can be ruled out by assessing memory performance for preceding or following items and comparing performance to targeted 
items or those that were not distinct and did not immediately precede or follow target item or items.

Depending on which effect is attributable for increased recognition, there are the following predictions for Experiment 2: Again, intent to remember instructions will elicit greater recognition rates than incidental instructions replicating Block (2009); frames will elicit an isolation effect, which may be more pronounced in the intention condition due to the additive effect of increased attention; and hit rates will be higher for targets (isolated items) than for preceding, following, non-targets, or new stimuli (background items). Alternatively, some studies have found that intent to remember may be critical to producing an isolation effect (Fabiani \& Donchin, 1995; Postman \& Phillips, 1954; Saltzman \& Carerette, 1959; Saul \& Osgood, 1950; Wallace, 1965). Consequently, there might be no isolation effect in the incidental conditions, and only in the intentional condition.

In this experiment, a recognition-memory test was used, in which framed target faces were compared to preceding faces, following faces, and neither-preceding-norfollowing items (other faces). Both hit rate and recognition discrimination were measured. On the recognition test, additional nonpresented items were also included. 
METHOD

\section{$\underline{\text { Subjects }}$}

A total of 314 introductory psychology students consented to participate in a study investigating how people process visual information. They were run in 30-minute sessions (groups) of about 8-10 subjects each.

\section{$\underline{\text { Materials }}$}

The same face monochrome pictures that were used in Experiment 1 were used in this experiment. Bird pictures were not used in this experiment, but only face pictures which became targets and background items. A total of 53 faces and 18 cars were presented in a 71-item series. The same instruction sheets and recognition test sheets as were used in Experiment 1 were used with identical instructions. Subjects in all three conditions were told to count the number of cars. This simple cover task was used by Experiment 1 and Block (2009) to ensure that subjects in the incidental conditions would not suspect that this was a memory experiment. Although they were selected from the same set, the pictures differed from those used in previous research.

\section{$\underline{\text { Stimuli }}$}

Seven framed target $(\mathrm{T})$ faces were randomly assigned to serial positions subject to the constraint that at least one preceding $(\mathrm{P})$ face and one following $(\mathrm{F})$ face presentation was available. Target faces were framed (see above), except in the 
incidental-unframed condition. Seven other faces which were neither-preceding-norfollowing $(\mathrm{O})$ faces were also used; they did not precede or follow a target or a car.

Untested filler faces were assigned to a total of 16 serial positions, sometimes to ensure that none of the $\mathrm{P}, \mathrm{F}$, or $\mathrm{O}$ faces would immediately precede or follow a car. Untested filler faces were also assigned to the five initial and the five final (primacy and recency buffer) serial positions that cars did not occupy.

Seven P and seven F faces were assigned to surround the framed T faces. Another seven $\mathrm{N}$ faces were randomly assigned around filler faces. The subsequent recognition test had 35 faces ( 7 preceding faces, 7 framed target faces, 7 following faces, 7 other faces that were not preceding nor following any target or car, and 7 new faces). Faces were randomized to counterbalance the series across conditions such that a given face occurred equally often as a $\mathrm{P}$ face, $\mathrm{F}$ face, $\mathrm{T}$ face, and $\mathrm{O}$ face.

\section{Design and Procedure}

A mixed model design was used with 3 between-subjects conditions (intentional framed, incidental framed, incidental unframed) $\times 4$ within-subjects presented stimulus types (framed faces, preceding faces, following faces, other faces). To disguise the nature of the memory experiment, all subjects were told to count cars. In the three betweensubject conditions the instruction sheets varied based on whether participants were told to attend to ALL faces as they would be tested on recognition of these faces later while counting the cars presented (intent), or they were told simply to count the cars presented (incidental). In the intent condition, as well as one of the incidental conditions target 
faces were presented with a white frame around them. In the second incidental (control) condition, targets were presented without frames.

In the initial presentation, a total of 71 pictures were presented, each for $2 \mathrm{~s}$ with and ISI of $0 \mathrm{~s}$. A total of 18 cars were randomly assigned to one of the 71 serial positions. Seven nontested faces were assigned to 5 initial and 5 final ("buffer”) serial positions (15 and 67-71) that cars did not occupy. Seven framed target faces were randomly assigned to positions, subject to the constraint that at least one $\mathrm{P}$ and one $\mathrm{F}$ face presentation position was available (for the second or pure incidental condition, the frames were deleted). Seven $\mathrm{P}$ and $\mathrm{F}$ faces then randomly assigned to surround the framed $\mathrm{T}$ faces. Another seven $\mathrm{O}$ faces were inserted in the series, a few times by inserting a filler item. Untested filler faces were assigned to a total of 16 serial positions, sometimes to ensure that none of the $\mathrm{P}, \mathrm{F}$, or $\mathrm{O}$ faces would immediately precede or follow a car. A recognition test (with serial positions randomly assigned) followed consisting of $7 \mathrm{~T}$ items, $7 \mathrm{P}$ items, $7 \mathrm{~F}$ items, $7 \mathrm{O}$ items, and $7 \mathrm{X}$ (new, unpresented) items, for a total of 35 faces, each presented for $8 \mathrm{~s}$. Three additional presentation series were constructed by randomizing the faces. The positions of the cars and the frames, though, were consistent and stayed the same as in the first series. The position of each recognition-test face remained constant, although the type of item $(\mathrm{P}, \mathrm{T}, \mathrm{F}, \mathrm{O}$, or $\mathrm{X})$ changed according to the randomization. 


\section{RESULTS}

Recognition performance was again analyzed using the recommended method and correction of Snodgrass and Corwin (1988). Again, no analysis revealed any pattern of findings different from the $P_{\mathrm{r}}$ and $B_{\mathrm{r}}$ measures; that is, each main effect and interaction effect was consistently either significant or nonsignificant regardless of which model of recognition discrimination and bias was used. Mixed-model ANOVAs were conducted to compare performance in the various conditions. Planned comparisons ( $t$ tests) were conducted to clarify differences between theoretically important conditions involving preceding or following stimuli.

\section{Overall Cover-Task Performance}

The overall number of cars reported $(M=17.85, S E=.075)$ did differ significantly from the actual number of 18 cars presented $[t(313)=1.96, p=.051]$. Participants in the two (combined) incidental conditions $(M=17.91, S E=0.16)$ and one intentional condition $(M=17.74, S E=0.08)$ showed comparable performance and did not differ significantly $[F(1,312)=1.17, p=.281]$.

\section{$\underline{\text { Recognition Discrimination }}$}

Preliminary evidence concerns recognition discrimination $\left(P_{\mathrm{r}}\right)$ as a function of memory condition, stimulus type, and their interaction. The results of a $3 \times 4$ mixedmodel ANOVA on recognition rate yielded a main effect of memory condition, such that overall items were recognized more often in the intent condition $(M=.3067, S E=0.14)$ 
than incidental framed $(M=.2075, S E=0.16)$ and incidental unframed $(M=.2135, S E=$ 0.23 ) conditions $\left[F(2,311)=12.00, p<.001, \eta_{\mathrm{p}}^{2}=.072, d=.443\right]$. This was followed up by collapsing the overall recognition rates across the incidental conditions in a betweensubjects ANOVA. $P_{\mathrm{r}}$ was significantly greater in the intentional condition than in the two incidental conditions $[t(312)=4.90, p<.001, d=.437]$ as is shown in Figure 3.

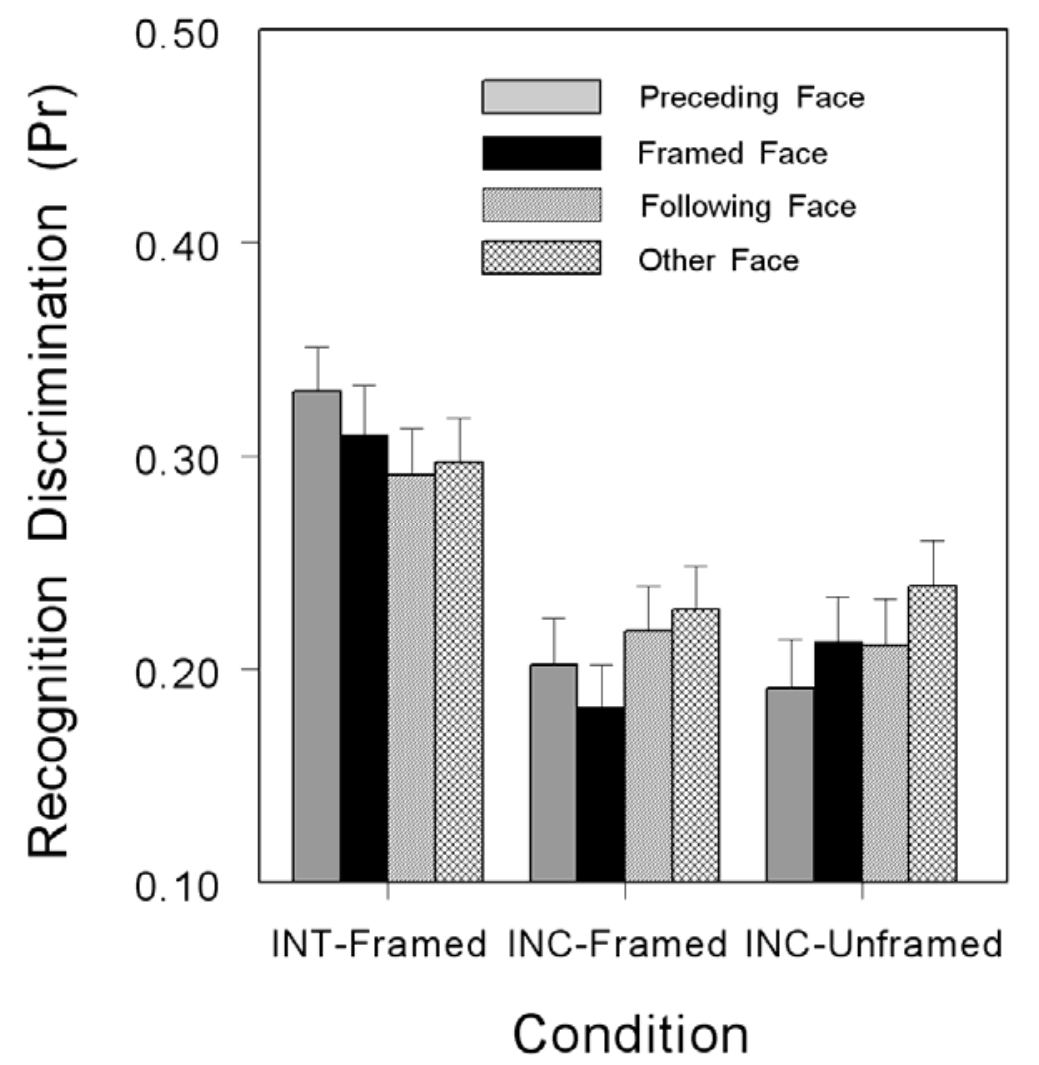

Figure 3. Overall recognition performance $\left(P_{\mathrm{r}}\right)$ in Intentional-Framed (intent + isolation) and incidental conditions (Incidental -Framed, or pure isolation; Incidental-Unframed, control) on face stimuli (Preceding, Framed, Following, \& Neither). In the IncidentalUnframed condition, there were no frames, thus framed faces are no longer isolated targets. Error bars show the SE of each mean. 
A $3 \times 4$ (Memory Condition $\times$ Item Type) mixed-model ANOVA additionally revealed a marginally significant interaction between item type and memory condition $[F(2,311)=2.56, p=.079, d=0.02]$, but no significant main effect of stimulus type $(F<$ $1)$.

Several more one-way ANOVAs revealed the marginally significant interaction was being driven by some of the stimuli types significantly differing between and within conditions, and others not. First, $P_{\mathrm{r}}$ for framed faces was significantly different between the three conditions $\left[F(2,311)=11.17, p<.001, d=0.99, \eta_{\mathrm{p}}{ }^{2}=.067\right]$. This effect was qualified by conducting planned comparisons which revealed that the intentional-framed condition was driving the effect, thus $P_{\mathrm{r}}$ for framed faces in the intentional framed condition was significantly higher than in the incidental-framed condition $[t(210)=4.58$, $p<.001]$ as well as the incidental-unframed $[t(203)=3.35, p<.001]$, but the latter two conditions did not differ significantly from each other, $p=.28$. This effect could be due to the additive effect of isolation and intent to yield a significantly higher $P_{\mathrm{r}}$ rate in the intentional-framed condition supporting past research suggesting intent is an important variable in the isolation effect.

A repeated-measures ANOVA and several planned comparisons revealed no significant differences between item types in the intentional-framed condition, the incidental-framed condition, or the incidental-unframed condition (all ps > .15) see Figure 3. There was a significant difference in $P_{\mathrm{r}}$ between framed faces and other faces $[t(108)=2.04, p=.04]$, which showed $P_{\mathrm{r}}$ for framed faces to be lower; this might be attributable to distraction. In the incidental-unframed condition, preceding stimuli were 
recognized at a lower rate than the other faces [t(101) $=2.14, p=.035]$. The pattern of significant and nonsignificant effects on the recognition hit rate (not reported herein) was the same as on recognition discrimination.

\section{False-alarm Rate and Recognition Bias}

A one-way ANOVA was conducted on the false-alarm rates and a mixed model 2 $\times 4$ (Memory Condition: intentional vs. incidental $\times$ Item Type: framed vs. preceding vs. following vs. neither) were conducted on the recognition bias $\left(B_{\mathrm{r}}\right)$.

The overall false-alarm rate was fairly low $(M=0.26, \mathrm{SE}=0.008)$. The main effect of memory condition was significant $\left[F(2,311)=3.76, p<.05, \eta_{\mathrm{p}}{ }^{2}=.024\right]$. This effect was driven by the intentional-framed condition having a significantly lower falsealarm rate than the two incidental memory conditions $[t(203)=2.46, p<.05 ; t(210)=$ $0.33, p<.05]$. The 2 incidental conditions did not differ significantly, $p=.22$. The intentional-framed condition may be subject to the "mirror effect" in that it shows an increased hit rate and thus a decreased false-alarm rate (Glanzer \& Adams, 1990), therefore the increased $P_{\mathrm{r}}$ for Condition 1 may be attributable in part to this decreased false-alarm rate.

A mixed model $2 \times 4$ (Memory Condition: intentional vs. incidental $\times$ Item Type: framed vs. preceding vs. following vs. neither) was conducted on recognition bias $\left(B_{\mathrm{r}}\right)$. The overall $B_{\mathrm{r}}$ was conservative $(M=0.34, \mathrm{SE}=.008)$. The main effect of memory condition was not significant $(F<1)$, and neither the main effect of stimulus type $(F<1)$ 
nor the Memory Condition $\times$ Stimulus Type interaction was significant $[F(6,308)=1.52$, $p=.17]$.

\section{Effects on Stimuli Preceding and Following Target Stimuli}

Several planned comparisons (within-subjects $t$ tests) on $P_{\mathrm{r}}$ values revealed the important finding of no significant effect on pictures that preceded or followed a framed target stimulus. This concurs with some earlier reports about isolation effects as well as Experiment 1. 


\section{DISCUSSION}

The effect of intent-to-remember on recognition memory was significantly greater than the effect on either of the incidental conditions. This conceptually replicates Block's (2009) findings, as well as those of Experiment 1.

Intent to remember increased recognition rates for all pictorial stimulus types (i.e., target and non-target faces). Isolation did not increase recognition rates; therefore, the isolation effect cannot explain the benefit of recognizing framed target faces found from intent to remember. The intentional-framed condition had the highest recognition rates compared to the incidental conditions, and no stimulus type was significantly higher than the others. The incidental-framed condition had higher recognition for other faces (neither-preceding-nor-following stimuli), and the incidental-unframed condition had significantly higher recognition for other faces and unframed target faces. This supports the notion that intent to remember may be critical to producing an isolation effect (Fabiani \& Donchin, 1995; Postman \& Phillips, 1954; Saltzman \& Carerette, 1959; Saul

\& Osgood, 1950; Wallace, 1965). It could also mean that (a) the unexpected frames were an attentional distraction, (b) that I used more than the usual number of isolated items than in most von Restorff studies (seven vs. one or just a few), or (c) both.

The main finding is that intent to remember may be needed for isolation, but isolation is not needed for intent-to-remember effects. These findings might help researchers understand the role of intent to remember and the isolation effect as influences on remembering. 


\section{EXPERIMENT 3}

The purpose of this third experiment was essentially to reevaluate Experiment 2, changing the frames to a more typical isolation manipulation (red tint). Bruce and Young (1986) stated, in regards to facial recognition, context matching at encoding and retrieval is important because this processes relies on identity-specific semantic information. Additionally context may also be important to produce an isolation effect in that it has to be effectively interrupted initially, and then match at retrieval (Bruce \& Gaines, 1976; Geraci \& Rajaram, 2004; Hunt, 1995; Schmidt, 1991). Therefore, Experiment 3 also has controls for context interruption in the form of reminding the participant of context in the recognition test instructions.

In Experiment 3, the first prediction is that the red tint will elicit an isolation effect (increased recognition for targets). Based on Experiment 2 and all extant isolationeffect literature, this is the first experiment in which the red tint is paired with intent to remember. Second, if an isolation effect is found it may have adverse effects on preceding and following faces, which based on Experiment 2 will likely only be in the pure isolation condition without intent. Lastly, intent to remember might result in increased recognition compared to the incidental memory conditions. 
METHOD

\section{$\underline{\text { Subjects }}$}

A total of 196 introductory psychology students consented to participate in a study investigating how people process visual information. They were run in 30-minute sessions (groups) of about 8-10 subjects each.

\section{Materials}

The same materials were used as in Experiment 2.

\section{$\underline{\text { Stimuli }}$}

The same stimuli design, order, types, and counterbalancing were used as in Experiment 2 with one important exception in that the frames were deleted, and the targets were in red tint to make these faces distinctive, rather than gray-scale background stimuli.

\section{Design and Procedure}

A mixed-model design was used, with three between-subjects conditions (intentional red, incidental red, and incidental no red) and four within-subjects stimulus types [red target faces $(\mathrm{T})$, preceding faces $(\mathrm{P})$, following faces $(\mathrm{F})$, and other faces (neither preceding nor following) (O)]. The procedure was exactly the same as in Experiment 2 except, "Please circle YES if you remember a face, even though it may 
originally have appeared with a red tone" was added to the instructions of the recognition test for the intentional-red and incidental-red conditions. Instructions for the control condition (incidental no red) were the same as Experiment 2. 


\section{RESULTS}

Overall recognition rates $\left(P_{\mathrm{r}}\right)$ for all stimulus types and memory conditions are shown in Figure 4. Several mixed model and one-way ANOVAs revealed the significant and nonsignificant effects.

\section{$\underline{\text { Overall Cover-Task Performance }}$}

The overall number of cars reported $(M=17.82, S E=0.06)$ was slightly less than the actual number of 18 cars presented $[t(195)=2.81, p=.006]$. The main effect of condition was not significant $[F(2,193)=2.05, p=.13]$. Additionally, the incidental groups collapsed revealed no significant effect between intent and incidental groups $[F(1$, 195) $=2.96, p=.587]$.

\section{$\underline{\text { Hit Rate and Recognition Discrimination }}$}

A $3 \times 4$ mixed-model ANOVA on recognition rate revealed no main effect of item type $(p>.05)$, and a significant main effect of memory condition, such that overall items were recognized more often in the intentional-red condition $(M=.2561, S E=0.10)$ than incidental-red $(M=.1950, S E=0.18)$ and incidental-no red $(M=.2135, S E=0.15)$ conditions $\left[F(2,193)=5.20, p<.01, \eta_{p}^{2}=.051\right]$. This main effect was succeeded by collapsing the overall recognition rates across the incidental conditions in a betweensubjects ANOVA. $P_{\mathrm{r}}$ was significantly greater in the intentional condition than in the two incidental conditions $\left[F(1,194)=7.50, p<.01, \eta_{\mathrm{p}}^{2}=.037, \mathrm{~d}=.437\right]$. 


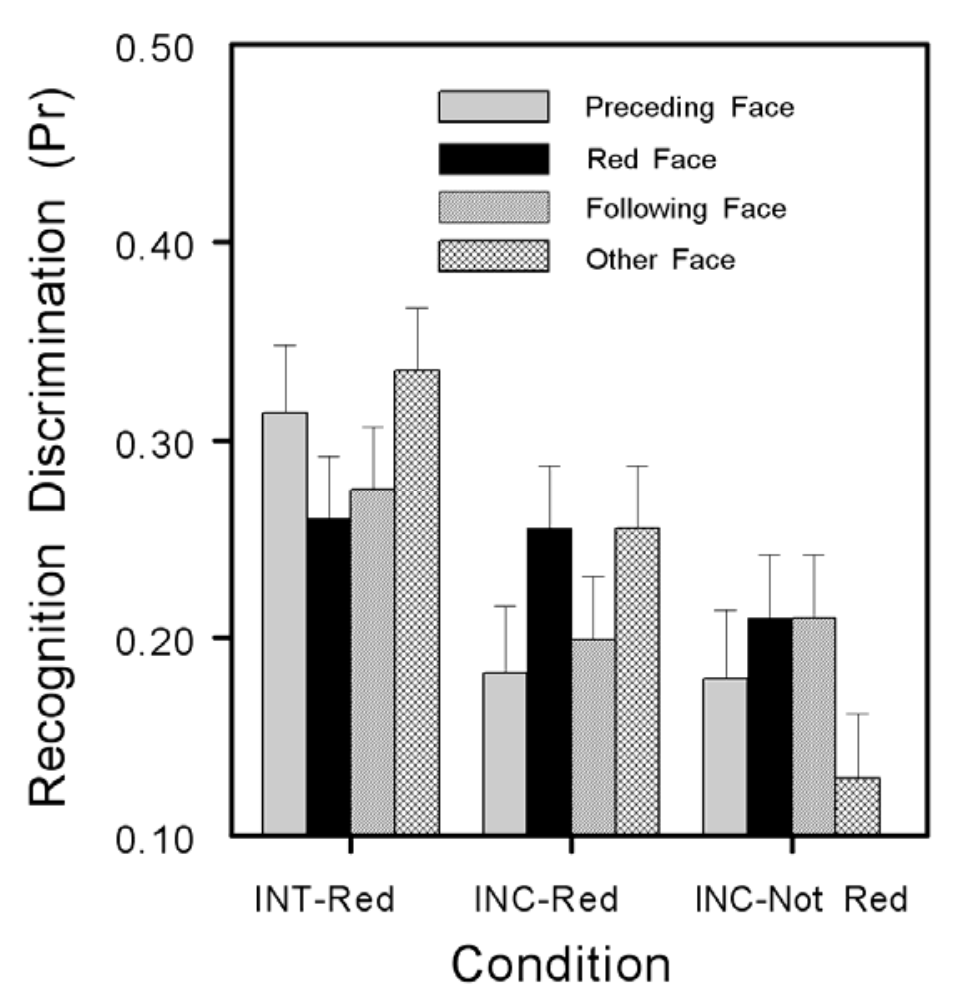

Figure 4. Overall recognition performance $\left(P_{\mathrm{r}}\right)$ in Intentional-Red (intent + isolation) and incidental conditions (Incidental-Red, or pure isolation; Incidental-No Red, control) on face stimuli (Preceding, Targets, Following, \& Neither). Error bars show the SE of each mean.

Additionally, the 3 X 4 mixed-model ANOVA produced a significant interaction between item type and memory condition $[F(2,193)=3.40, p<.05, d=0.02]$, but no significant main effect of stimulus type $(F<1)$. This interaction was followed up with several planned comparisons which revealed marginally significant differences between red faces and other faces $[t(65)=1.85, p=.068]$, and between following faces and other faces $[t(65)=1.67, p=.09]$ in the intentional-red condition. In the incidental-red condition there were several significant and marginally significant effects, such that red 
faces were recognized at a significantly higher rate than preceding faces $[t(65)=2.19, p<$ $.05]$ and marginally significantly higher than following faces $[t(65)=1.77, p=.08]$. This reveals a slight isolation effect, such that red faces were recognized better than homogenous surrounding items. Additionally, other faces were recognized significantly higher than preceding faces $[t(65)=2.08, p<.05]$ and marginally significantly higher than following faces $[t(65)=1.91, p=.06]$. The incidental no red condition revealed significant effects in that other faces were lower than the non-red equivalent to the red target faces in the other conditions $[t(63)=2.45, p<.05]$ and following faces $[t(63)=$ 2.84, $p<.05]$. This could mean the interaction was qualified by various differences in item types, but not an overall item type effect.

A one-way ANOVAs revealed that $P_{r}$ for red faces was not significantly different between the three conditions $[F(2,193)=.744, p=.477]$. This effect was also nonsignificant when collapsed across the two incidental conditions to compare to the intentional one $[F(1,194)=.472, p=.493]$. The pattern of significant and nonsignificant effects on the recognition hit rate (not reported herein) was the same as on recognition discrimination. 


\section{False-alarm Rate and Recognition Bias}

A one-way ANOVA was conducted on the false-alarm rates, and a mixed model 2 $\times 4$ (Memory Condition: intentional vs. incidental $\times$ Item Type: red faces vs. preceding faces vs. following faces vs. other faces) ANOVA was conducted on the recognition bias (Br).

The false-alarm rate was fairly low $(M=0.36, \mathrm{SE}=0.011)$. The effect of memory condition was not significant $[F(2,193)=.495, p=.61]$. The effect of stimuli type was also not significant, $[F(3,192)=.706, p=.55]$. The Memory Condition $\times$ Stimulus Type interaction was significant, $[F(6,189)=2.27, p=.003]$. This interaction was qualified by the other faces (neither-preceding-nor-following) being high in intentional-red and incidental-red red conditions and very low in the incidental-no red condition.

\section{$\underline{\text { Effects on Stimuli Preceding and Following Target Stimuli }}$}

Several planned comparisons (within-subjects $t$ tests) on $P_{\mathrm{r}}$ values revealed the important finding of significant effects on faces that preceded or followed a red face. In the incidental-red condition there were several significant and marginally significant effects, such that red faces were recognized at a significantly higher rate than preceding faces $[t(65)=2.19, p<.05]$ and marginally significantly higher than following faces $[t(65)=1.77, p=.08]$. This reveals a slight isolation effect, such that red faces were recognized better than homogenous surrounding items. This concurs with some earlier reports about isolation effects. 
Additionally, other faces were recognized significantly higher than preceding faces $[t(65)=2.08, p<.05]$ and marginally significantly higher than following faces $[t(65)=1.91, p=.06]$. The incidental no red condition revealed significant effects in that other faces were lower than the non-red equivalent to the red target faces in the other conditions $[t(63)=2.45, p<.05]$ and following faces $[t(63)=2.84, p<.05]$. This could mean the interaction was qualified by various differences in item types, but not an overall item type effect.

\section{Comparisons with Data from Experiment 2}

For the sake of clarity, Experiment 2 overall was compared to overall $P_{\mathrm{r}}$ in Experiment 3 to find significant differences which are most likely due to the variation in the isolation manipulation. A one-way ANOVA revealed a significant main effect of experiment on overall $P_{\mathrm{r}}\left[F(2,311)=3.76, p<.05, \eta_{\mathrm{p}}{ }^{2}=.024\right]$ such that overall $P_{r}$ was significantly higher in Experiment 2. Additional t-tests showed that in the intentionalisolation conditions there were no significant differences between recognition rates for the preceding and following faces in Experiment 2 and the preceding and following faces in Experiment 3, showing $P_{r}$ to be at baseline rates in both experiments $(F>1)$. This means that surrounding faces were not decreased due to Red Face Target recognition in Experiment 3. Also comparing the intentional-isolation conditions in Experiement 2 and 3, it was found framed (distinct) faces in Experiment 2 were recognized at a significantly lower rate than red (distinct) faces in Experiment $3\left[F(1,173)=80.63, p<.001, \eta_{\mathrm{p}}{ }^{2}=\right.$ .318]. This shows that Experiment 3 did elicit an isolation effect such that the distinct red 
faces were remembered at a significantly higher rate when compared to the framed faces in Experiment 2. 


\section{DISCUSSION}

The main findings of Experiment 3 were the replication of an intent effect as well as a marginal isolation effect in one incidental condition. The findings of Experiment 3 partially replicate and clarify the findings of Experiment 2. As in Experiment 2, the effect of intentional memory on recognition discrimination was significant. However, the isolation effect appeared without intent, unlike in Experiment 2. This means the isolation manipulation in Experiment 3 (red tint) may have been a more pure example of an isolation manipulation than the frames used in Experiment 2. On the other hand, this could also mean that restating the context at retrieval enabled participants to recognize red target faces at a higher rate $(p<.001)$, but this is not likely as the control most likely did not work and was not adequate which shows a stronger result in that an isolation effect was produced even without context reinstatment.

Overall recognition rates were significantly higher in the intent condition than the incidental conditions once again supporting the rapid allocation of attentional resources when intent is present. This theory might also apply to the isolation effect due to increased recognition of red targets or distinct (red) faces versus the low recognition of the background or homogenous monochrome faces. Other faces (those neither preceding or following distinct target faces) were also recognized at an high rate which may have actually been a result of the participants realizing they were going to be given a memory test, or this shows recognition rates for distinct target faces was prematurely low. Future research may explore this possibility. 


\section{GENERAL DISCUSSION}

The current study examined the intent to remember effect combined with the isolation effect in three experiments to reveal several important findings. First, the present study replicated Block (2009) in that intent to remember had facilitating effects on subsequent recognition. Second, this effect did not seem to be detrimental to background items and trumped the isolation effect in producing higher or at least equal recognition for target items in all three experiments. Third, with the proper controls a marginal isolation effect was produced in an incidental condition, therefore intent is not necessarily vital to produce the effect.

Importantly, by considering effects on stimuli preceding and following red or framed target stimuli, the current study also examined the mechanisms driving intent and isolation effects. Experiment 1 was intended to test alternative explanations to Block’s (2009) attentional allocation explanation by utilizing the isolation effect and looking at the effects on background items. Although it may have been ineffective at producing an isolation effect, it still effectively demonstrated that immediate background items were not improved or degraded. Because recognition of preceding and following items were not affected, several hypotheses about intent to remember were potentially rejected.

First, recognition of target stimuli did not affect consolidation of a preceding stimulus. Second, the rehearsal of a target stimulus did not impair memory for a following stimulus, which was highly unlikely considering all stimuli were replaced immediately (at ISI $=0$ ), and recognition for following stimuli was not significantly lower nor higher than target stimuli. Consequently, it was concluded that Experiment 1 
supported the attentional-gate model, thus heightening of recognition in the intentional conditions was attributable to the rapid allocation of attentional resources which corresponds with Block (2009).

The purpose of Experiment 2 was to review the possibility that the isolation effect may or may not be driving the intent to remember effect and therefore may be responsible for increased recognition for framed target faces. The addition of the isolation effect in Experiment 1 may have influenced a change. On the other hand, isolation may not have been tested exclusively and the effects needed to be clearly separated to determine the processes driving the effects. When the effects were separated out, there were still no effects on background items that damaged nor strengthened recognition compared to framed target faces. Regardless, the results of Experiments 1 and 2 combined seemed to establish that intent to remember has no aversive effects on recognition for background items.

The main finding of Experiment 2 was that isolation did not increase recognition rates. As such the isolation effect cannot explain the recognition increase on framed faces found from intent to remember, yet no stimulus type was recognized significantly higher than another when measured within each condition. Interestingly, the frames seemed to distract participants from encoding the framed target faces exclusively in the pure isolation condition. Such was not the case in the intention condition, nor the control incidental condition. These results support past research in that intent to remember may be vital to producing an isolation effect (Fabiani \& Donchin, 1995; Postman \& Phillips, 1954; Saltzman \& Carerette, 1959; Saul \& Osgood, 1950; Wallace, 1965). Due to the 
untested nature of the isolation effect used, further exploration was needed after altering the isolation manipulation to one more consistent with past research. Additionally there may have been an issue that was unaccounted for. Research has suggested that for the isolation effect to emerge, context must match or be reinstated at both encoding and retrieval (Bruce \& Gaines, 1976; Geraci \& Rajaram, 2004; Hunt, 1995; Schmidt, 1991). This means that the context in which an item is studied (red tint) should be matched at retrieval (still distinct or red tint). The context was restated at retrieval in this case, but not reinstated, therefore was likely not adequate to control for this issue. This shows that our results are stronger if a marginal isolation effect was found even without proper controls for context matching.

Experiment 3 was identical to Experiment 2, with the addition of a new isolation manipulation and controls for context differences. Unlike Experiment 2, the isolation effect seemed to appear without intent and did not emerge in the intent condition. In fact, recognition rates for red faces were identical in the Intent Red condition and the Incidental Red condition but were greatly reduced in the control incidental condition, but only marginally so. Therefore the red tint isolation manipulation may have been a superior example of an isolation manipulation than the frames used in Experiment 2 and recognition rates for red faces may have been prematurely low. Future research may lead to a clearer conclusion.

Intent to remember produced the highest recognition rates in all 3 experiments regardless of isolation manipulation. In Experiment 1 recognition for faces seemed to be trending towards a significantly higher recognition for birds as seen in Figure 2. Further 
investigation of this trend using the intent and isolation paradigms might clarify this relationship. Experiment 2 revealed that intent was superior to isolation when pitted against each other, but did not show an additive advantage for framed target faces. Rather a pattern seemed to be trending but never reached significance in that $P_{r}$ for preceding faces was higher than $P_{r}$ for framed faces, where $P_{r}$ for following faces seemed to suffer.

In Experiment 3, intentionality paired with the red target faces produced higher recognition, but again no isolation effect. Unlike the frames in the incidental-framed condition, intent paired with the red tint reduced recognition, and made the red target faces stimuli more difficult to recognize only when intention was present. Other faces were recognized at the highest rate, potentially supporting this theory considering they were not placed around red faces. Further research will need to parse out these differences.

The pure isolation conditions were the most interesting throughout Experiment 2 and 3 in that the results were almost opposite in these two experiments. Frames seemed to act as a distraction, greatly reducing $P_{r}$ for framed (distinct) faces in Experiment 2, but red tint had a facilitating effect on $P_{r}$ for red (distinct) faces in Experiment 3. This may have just been a difference in isolation and the red tint was a better manipulation considering recognition for preceding and following faces were at comparable rates in both Experiment 2 and $3(F>1)$. Additionally red faces were recognized at a significantly higher rate than framed faces in the incidental-isolation conditions between Experiment 2 and 3. Thus this is why it is possible that restating the context before recognition was now partially attributable for the $P_{r}$ increase for red faces in Experiment 
3, but not likely since according to past research the proper controls were not met (Bruce \& Gaines, 1976; Geraci \& Rajaram, 2004; Hunt, 1995; Schmidt, 1991. The control condition $P_{r}$ stayed at similar baseline rates throughout all three experiments which acted as a suitable manipulation check through the series.

Past intent to remember studies have used rehearsable verbal materials such as words, and recall tests of memory resulting in somewhat reliable effects of intent to remember. However, experiments that used pictorial materials such as human faces, and recognition tests, produced little or no effect of intent (Bower \& Karlin, 1974). The opposite was true of the isolation effect with results in contrast, or inconclusive except when pictorial stimuli were used. For pictorial stimuli, isolation was found in both recall and recognition (Ellis et al., 1971). The limits of the effects of the intent to remember was investigated by applying the stringent conditions Block (2009) devised that resulted in a reliable effect of intent and were utilized on the isolation effect. By using presumably unrehearsable pictorial stimuli, effects of both isolation and intent emerged.

New findings regarding effects of isolation and perhaps intent, as well as the role of controlled information processing, were revealed. Reeves and Sperling (1986) theorized that an attentional gate can open within about 300-400 msec, allowing for effective short-term memory encoding of rapidly presented visual information. Results for intent continue to support this rapid allocation of attentional resources, as the current set of experiments ruled out alternative explainations. Isolation on the other hand, without the possibility of rehearsal, also points to directed attention and evidence that isolation suffers when participants were distracted and attention was directed elsewhere. In 
conclusion future research should expand on these findings, with a blatantly distinct isolation manipulation paired with differing levels of distraction. Additionally exploration of the attentional gate hypothesis should also be completed by perhaps directly measuring or manipulating attentional resources to find if attention truly is the mechanism producing these two processes. 


\section{REFERENCES CITED}

Block, R. A. (2009). Intent to remember briefly presented human faces and other pictorial stimuli enhances recognition memory. Memory and Cognition, 37, 667-678.

Bower, G. H., \& Karlin, M. B. (1974). Depth of processing pictures of faces and recognition memory. Journal of Experimental Psychology, 103, 751-757.

Brown, R , \& Kulik, J. (1977). Flashbulb memories. Cognition, 5, 73-99.

Bruce, D., \& Gaines, M. T. (1976). Tests of an organizational hypothesis of isolation effects in free recall. Journal of Verbal Learning and Verbal Behavior, 15, 59-72.

Bruce, V., \& Young, A. (1986). Understanding face recognition. British Journal of Psychology, 77, 305-327.

Carmel, D., \& Bentin, S. (2002). Domain specificity versus expertise: Factors influencing distinct processing of faces. Cognition, 83, 1-29.

Cohen, M. E., \& Carr, W. J. (1975). Facial recognitionand the von Restorff effect. Bulletin of the Psychonomic Society, 6, 383-384.

Craik, F. I. M., \& Lockhart, R. S. (1972). Levels of processing: A framework for memory research. Journal of Verbal Learning and Verbal Behavior, 11, 671-684.

Dunlosky, J., Hunt, R. R., \& Clark, E. (2000). Is perceptual salience needed in explainations of the isolation effect? Journal of Experimental Psychology: Learning, Memory, and Cognition, 26, 649-657.

Eagle, M., \& Leiter, E. (1964). Recall and recognition in intentional and incidental learning. Journal of Experimental Psychology, 68, 58-63.

Ellis, H. D. (1975). Recognizing faces. British Journal of Psychology, 66, 409-426.

Ellis, N. R., Detterman, D. K., Runcie, D., McCarver, R. B., \& Craig, E. (1971). Amnesic effects in short-term memory. Journal of Experimental Psychology, 89, 357-361.

Estes, W. K., \& Da Polito, F. (1967). Independent variation of information storage and retrieval processes in paired-associate learning. Journal of Experimental Psychology, 75, 18-26.

Fabiani, M., \& Donchin, E. (1995). Encoding processes and memory organization: A model of the von Restorff effect. Journal of Experimental Psychology: Learning, Memory, and Cognition, 21, 224-240. 
Farah, M. J., Wilson, K. D., Drain, M., \& Tanaka, J. N. (1998). What is “special” about face perception? Psychological Review, 105, 482-498.

Gati, I., \& Ben-Shakhar, G. (1990). Novelty and significance in orientation and habituation: A feature-matching approach. Journal of Experimental Psychology: General, 119, 251-263.

Geraci, L., \& Manzano, I. (2010). Distinctive items are salient during encoding: Delayed judgments of learning predict the isolation effect. The Quarterly Journal of Experimental Psychology, 63, 50-64.

Geraci, L., \& Rajaram, S. (2004). The distinctiveness effect in the absence of conscious recollection: Evidence from conceptual priming. Journal of Memory and Language, 51, 217-230.

Going, M., \& Read, J. D. (1974). Effects of uniqueness, sex of subject, and sex of photographon facial recognition. Perceptual and Motor Skills, 39, 109-110.

Goodman, G. S. (1980). Picture memory: How the action schema affects retention. Cognitive Psychology, 12, 473-495.

Glanzer, M., \& Adams, J. K. (1990) The mirror effect in recognition memory: Data and theory. Journal of Experimental Psychology: Learning, Memory, and Cognition, 16, 5-16.

Green, R T. (1956). Surprise as a factor in the von Restorff effect. Journal of Experimental Psychology, 52, 340-344.

Hasher, L., \& Zacks, R. T. (1979). Automatic and effortful processes in memory. Journal of Experimental Psychology: General, 108, 356-388.

Hasher, L., \& Zacks, R. T. (1984). Automatic processing of fundamental information: The case of frequency of occurrence. American Psychologist, 39, 1372-1388.

Hintzman, D. L., \& Rogers, M. K. (1973). Spacing effects in picture memory. Memory and Cognition, 1, 430-434.

Hunt, R. R. (1995). The subtlety of distinctiveness: What von Restorff really did. Psychonomic Bulletin and Review, 2, 105-112. 
Hunt, R. R., \& Lamb, C. A. (2001). What causes the isolation effect? Journal of Experimental Psychology: Learning, Memory, and Cognition, 27, 1359-1366.

Hunt, R. R., \& Mitchell, D. B. (1978). Specificity in nonsemantic orienting tasks and distinctive memory traces. Journal of Experimental Psychology: Learning, Memory, and Cognition, 4, 121-135.

Hunt, R. R., \& Mitchell, D. B. (1982). Independent effects of semantic and nonsemantic distinctiveness. Journal of Experimental Psychology: Learning, Memory, and Cognition, 8, 81-87.

Hyde, T. S., \& Jenkins, J. J. (1973). Recall for words as a function of semantic, graphic, and syntactic orienting tasks. Journal of Verbal Learning and Verbal Behavior, $12,471-480$.

Jenkins, W. O., \& Postman, L. (1948). Isolation and spread of effect in serial learning. American Journal of Psychology, 61, 214-221.

Light, L. L., Kayra-Stuart, F., \& Hollander, S. (1979). Recognition memory for typical and unusual faces. Journal of Experimental Psychology: Human Learning de Memory, 5, 212-228.

McDaniel, M. A., \& Einstein, G. O. (1986). Bizarre imagery as an effective memory: The importance of distinctiveness. Journal of Experimental Psychology: Learning, Memory, and Cognition, 12, 54-65.

McLaughlin, J. P. (1968). Recall and recognition measures of the von Restorff effect in serial learning. Journal of Experimental Psychology ,78, 99-102.

Neimark, E., \& Saltzman, I. J. (1953). Intentional and incidental learning with different rates of stimulus-presentation. American Journal of Psychology, 66, 618-621.

Palermo, R., \& Rhodes, G. (2007). Are you always on my mind? A review of how face perception and attention interact. Neuropsychologia, 45, 75-92.

Posner, M. I., \& Snyder, C. R. R. (1975). Attention and cognitive control. In R. L. Solso (Ed.), Information processing and cognition: The Loyola symposium (pp. 55-85). Hillsdale, NJ: Erlbaum.

Postman, L., \& Phillips, L. W. (1954). Studies in incidental learning: I. The effects of crowding and isolation. Journal of Experimental Psychology, 48, 48-56.

Rakover, S. S. (2002). Featural vs. configurational information in faces: A conceptual and empirical analysis. British Journal of Psychology, 93, 1-30. 
Reeves, A., \& Sperling, G. (1986). Attention gating in short-term visual memory. Psychological Review, 93, 180-206.

Saltzman, I. J. (1953). The orienting task in incidental and intentional learning. American Journal of Psychology, 66, 593-597.

Saltzman, I. J., \& Carterette, T. S. (1959). Incidental and intentional learning of isolated and crowded items. American Journal of Psychology,72, 230-235.

Saul, E. V., \& Osgood, C. E. (1950). Perceptual organization of materials as a factor influencing ease of learning and degree of retention. Journal of Experimental Psychology, 40, 372-379.

Schmidt, S. R (1985). Encoding and retrieval processes in the memory for conceptually distinctive events. Journal of Experimental Psychology: Learning. Memory. and Cognition, 11, 565-578.

Schmidt, S. R. (1991). Can we have a distinctive theory of memory? Memory and Cognition, 19, 523-542.

Schneider, W., \& Shiffrin, R. M. (1977). Controlled and automatic human information processing: I. Detection, search, and attention. Psychological Review, 84, 1-66.

Schulz, L. S. (1971). Effects of high-priority events on recall and recognition of other events. Journal of Verbal Learning: Verbal Behavior, 10, 322-330.

Shaffer, W., \& Shiffrin, R. M. (1972). Rehearsal and storage of visual information. Journal of Experimental Psychology, 92, 292-296.

Shiffrin, R. M., \& Schneider, W. (1977). Controlled and automatic human information processing: II. Perceptual learning, automatic attending, and a general theory. Psychological Review, 84, 127-190.

Snodgrass, J. G., \& Corwin, J. (1988). Pragmatics of measuring recognition memory: Applications to dementia and amnesia. Journal of Experimental Psychology: General, 117, 34-50.

Tulving, E. (1969). Retrograde amnesia in free recall. Science, 164, 88-90.

Tversky, B., \& Sherman, T. (1975). Picture memory improves with longer on time and off time. Journal of Experimental Psychology: Human Learning and Memory, 1, 114-118. 
Tyler, S. W., Hertel, P. T., McCallum, M. C., \& Ellis, H. C. (1979). Cognitive effort and memory. Journal of Experimental Psychology: Human Learning and Memory, 5, 607-617.

van Dam, G., Peeck, J., Brinkerink, M., \& Gorter, U. (1974). The isolation effect in free recall and recognition. American Journal of Psychology, 87, 497-504.

von Restoreff, H. (1933). Ober die Wirkung von Bereichsbildungen im Spurenfeld. Psychologische Forschung, 18, 299-342.

Wallace, W. P. (1965). Review of the historical, empirical, and theoretical status of the von Restorff phenomenon, Psychological Bulletin, 63, 410-424.

Watkins, M. J., \& Graefe, T. M. (1981). Delayed rehearsal of pictures. Journal of Verbal Learning and Verbal Behavior, 20, 276-288.

Waugh, N. C. (1969). Free recall of conspicuous items. Journal of Verbal Learning and Verbal Behavior, 8, 448-456.

Weaver, G. E. (1974). Effects of poststimulus study time on recognition of pictures. Journal of Experimental Psychology, 103, 799-801. 